\title{
Paying over the odds
}

\author{
Tom Jacobs
}

Investors most often lose money by overpaying for growth or failing to sell when the growth doesn't warrant the valuation. Here's one way to determine valuation risk - that the valuation is too high to offer you decent returns and presents risk of loss- together with one prominent biotech example.

\section{A better valuation}

Valuation is most often cited as a company's market value or market capitalization, market cap for short. Market cap is simply stock price times shares outstanding. It assumes that if you had to buy the company, you would pay at least this price.

But this is not right. Given the choice between two companies with market caps of $\$ 1$ billion, a buyer would care very much whether one had $\$ 50$ million in debt and \$200 million in the bank, or the reverse. Cash (which you'd get back with your purchase) is better than debt (an onerous obligation to pay creditors), but market cap makes no distinction between the two. A better measure, enterprise value (EV), takes market cap, adds debt and subtracts cash.

\section{Goodbye P/E}

After jettisoning market cap for EV, we turn to the familiar P/E, or price-to-earnings multiple (multiple is sometimes called ratio). This is a company's stock price divided by earnings per share (EPS), determined by its accountants for tax purposes. EPS reflect all sorts of tax deductions and charges that don't involve a company

\footnotetext{
Tom Jacobs is cofounder of Complete Growth Investor, (http://www.completegrowth.com/), a stock service for individual investors. Tom has shorted Affymetrix in the past, but neither he nor Complete Growth Investor has any position in the stock at the time of writing. He welcomes yourcommentsat tom@completegrowth. com. Nature Biotechnology does not guarantee the veracity, reliability or completeness of the information provided on this page.
}

paying out or taking in cash. They are fictions that increase or decrease tax liability. If you do your own taxes, you know this to be true.

But we investors don't want to know accounting fiction, we want to know about the cash, so we look to a company's statement of cash flows each quarter, which takes EPS and adds back in the accounting noncash items. If you take the cash generated by company operations and subtract the company's reported spending on property, plant and equipment you have free cash flow (FCF). So I use FCF instead of EPS, and with EV instead of market cap, it's best to use the EV/FCF multiple instead of $\mathrm{P} / \mathrm{E}$.

\section{Guessing growth}

Next, compare a company's growth rate to the EV/FCF multiple. Nothing is harder than to estimate that rate. An average of past growth works reliably for stable mature companies, such as Coca-Cola, but rarely if ever for biotechs. Also, beware that FCF is lumpy, so look for trends in FCF growth rather than a particular quarter or year, and project several years. In a new industry like biotech, it's crucial to estimate how product success or failure could change the company's growth rate dramatically in a short time.

\section{How much to pay for growth?}

You want the growth rate to exceed the EV/ FCF multiple by as much as possible. The more it does, the more you are protected if growth should hit a bump or slow over time. On the other hand, the more the EV/FCF multiple exceeds the growth rate, the greater your valuation risk that the stock price will fall until the multiple is closer to the growth rate.

Some analysts divide growth by the EV/FCF multiple and say that under 1.0 is cheap and over 1.0 expensive (when they use P/E, they call it price-to-earnings-to-growth, or PEG). Thus, a company growing FCF at 20\% is fairly priced at an EV/FCF multiple of 20, cheap at 15 and expensive at 25. This is a rough gauge. In periods of investor enthusiasm, 25 might be cheap, and in pessimistic eras, 15 might be wildly expensive. These periods can last for years and even decades. Take this into account.

\section{Too high a price}

Affymetrix (Santa Clara, CA, USA; Nasdaq: AFFX) practically invented the commercial large-scale testing of complex genetic data through its photolithographically synthesized oligonucleotide chip (GeneChip) system. And despite Affymetrix's outstanding achievements as a technology pioneer and in building a profitable business where none before existed, today, I believe the company's stock at $\$ 45$ presents a very high valuation risk and thus should be avoided.

Here's why. For six years from 1999 to 2004, Affymetrix's sales have risen by $108 \%, 84 \%$, $12 \%, 29 \%, 4 \%$ and $15 \%$ annually, and are on track for a $10 \%$ gain in 2005 . For the last four quarters versus a year ago, that's $21 \%, 13 \%$, $5 \%$ and $4 \%$, with management projecting next quarter at a $14 \%$ rise.

EPS has been positive for three years, but under two measures of FCF, there are either only one or two years of positive FCF, and not two consecutive. Yet given this uncertain trend, if we average our two types of FCF, the EV/FCF multiple is 71 . This assumes growth rates in FCF far beyond revenue growth of the current $10-14 \%$ and, using $12 \%$ growth, yields an EV/FCF/growth multiple of 6.0, far beyond the rule of thumb that 1.0 implies a fair price. As there is no indication that growth will rise or stay even, the stock is odds-on to fall and to stay there for several years.

\section{Stand clear}

If a stock's valuation greatly exceeds your estimate of future growth, pain may follow. Not only does a high valuation assume very blue skies, but you will have to hold the stock a very long time while risking losses and missing other potentially better opportunities along the way. Affymetrix at $\$ 45$ is a prime candidate for pain. 